\title{
Cuando se aproxima el lenguaje escrito al oral: competencias lingüísticas en el discurso académico del alumnado del Grado en Educación Primaria
}

\author{
Aurora Martínez Ezquerroi \\ Universidad de La Rioja, Logroño, La Rioja, España
}

\begin{abstract}
Resumen
Los estudiantes universitarios deben mostrar en su actividad académica el dominio de las competencias comunicativas. Las diversas prácticas discursivas a las que se enfrentan en el desarrollo de sus tareas manifiestan en muchas ocasiones que dichas habilidades no se han alcanzado convenientemente $y$, en consecuencia, indican un inadecuado conocimiento de la competencia lingüística. Teniendo en cuenta esta carencia, en la presente investigación empírica, basada en un estudio de caso realizado con estudiantes del Grado en Educación Primaria (Universidad de La Rioja), se analiza - con metodología cualitativa - la competencia lingüístico-discursiva a partir del estudio de los rasgos lingüísticos de prácticas textuales académicas en las que se aprecian fenómenos propios del lenguaje oral. El amplio corpus muestra que hay profusión de rasgos del registro informal y, por tanto, los textos no se adecuan a la situación comunicativa. La formación del alumnado mediante programas de alfabetización podría solucionar estas insuficiencias competenciales, si bien dicha instrucción debe ser un trabajo planteado desde una perspectiva transdisciplinar.
\end{abstract}

Palabras clave

Competencia lingüística. Lenguaje oral. Alfabetización académica. Formación inicial.

\section{Quando a língua escrita se aproxima a língua oral: competências} linguísticas no discurso acadêmico de alunos do grau de Ensino Primário

\begin{abstract}
Resumo
Os estudantes universitários devem mostrar domínio das habilidades de comunicação em sua atividade acadêmica. As diversas práticas discursivas que enfrentam no desenvolvimento de suas tarefas mostram, em muitas ocasiões, que essas habilidades não foram adequadamente alcançadas e consequentemente indicam um conhecimento inadequado da competência linguística. Considerando essa deficiência, na presente pesquisa empírica, baseada num estudo de caso realizado com alunos do curso de licenciatura em Educação Básica (Universidade de La Rioja), analisa-se a competência linguístico-discursiva - com metodologia qualitativa - a partir do estudo das características linguísticas de práticas textuais acadêmicas nas quais fenômenos típicos da linguagem oral são apreciados. $O$ grande corpus mostra que há uma profusão de características do registro informal e, portanto, os textos não estão adaptados à situação comunicativa. A formação de alunos por meio de programas de alfabetização poderia solucionar essas
\end{abstract}

Educ. Form., Fortaleza, v. 6, n. 1, e3502, jan./abr. 2021

DOI: https://doi.org/10.25053/redufor.v6i1.3502

https://revistas.uece.br/index.php/redufor/index ISSN: 2448-3583 
deficiências de competência, embora tal instrução deva ser um trabalho desenvolvido a partir de uma perspectiva transdisciplinar.

\title{
Palavras-chave
}

Competência linguística. Linguagem oral. Alfabetização acadêmica. Treino inicial.

\section{When written language approaches to oral: linguistic competences in the academic discourse of students of the degree in Primary Education}

\begin{abstract}
University students must show communication skills in their academic work. The variety of discursive practices that they encounter during their degree often reveals that they have not properly developed these abilities and that they do not possess full linguistic competence. Therefore, in this empirical investigation of a case study carried out with Primary Education degree students (University of La Rioja), the linguistic and discursive competence of the linguistic features of academic practices that use features typical of oral language are analysed using a qualitative methodology. The extensive corpus shows that there are numerous cases of informal register use and that, therefore, the texts do not adapt to the communicative context. The training of students through literacy programmes would solve these deficiencies, although this training should be carried out from a transdisciplinary perspective.
\end{abstract}

\section{Keywords}

Linguistic competence. Oral language. Academic literacy. Primary training.

\section{Introducción: cuando el lenguaje escrito se aproxima al oral en el discurso académico del alumnado en formación}

Una afirmación que quizá resulte obvia responde a la necesidad de fomentar la competencia comunicativa (CANALE, 1995; HYMES, 1984) en el contexto de la Enseñanza Superior. Si esta cuestión se considera prioritaria - por lo menos, implícitamente -, nos preguntamos por qué no se abordan las medidas necesarias (MOYANO, 2010, 2018) para paliar las depauperadas habilidades discursivas que, como sabemos, atienden a la comunicación, cognición, contenido y cultura (QUILES CABRERA; CAIRE, 2013) de los estudiantes. No todos los docentes consideran que sea materia y técnica a la que se deba dedicar tiempo, pues se sobreentiende que los universitarios disponen de las adecuadas estrategias básicas para el dominio de las habilidades comunicativas en las que ya han sido alfabetizados (BALLANO; MUÑOZ, 2014, 2015).

En este espacio educativo surgen los estudios de literacidad académica (academic literacies), alfabetización académica o alfabetización (CARLINO, 2005; 
CASSANY; MORALES, 2009). Su finalidad consiste en instruir a los estudiantes en el conocimiento de métodos y prácticas lecto-escritoras que posibiliten la expresión adecuada del pensamiento, porque el desarrollo de las habilidades complejas no se logra, por lo general, de forma autónoma, ya que necesita un proceso de enseñanza. La alfabetización académica se forma en un aprendizaje continuo y contextualizado y ofrece herramientas epistémicas posibilitadoras de la adecuada expresión del conocimiento (BOEGLIN, 2008; CARLINO, 2005, 2013); considera que los textos académicos son estructuras específicas que requieren, asimismo, el dominio de las destrezas lingüísticas mediante la aplicación de los enfoques comunicativos y discursivos (HYMES, 1984; LOMAS, 2015; MONTOLÍO, 2014; VAN DIJK, 1980), y este aprendizaje lingüístico se aborda desde la didáctica de la lengua (CANALE, 1995; CASSANY, 1989, 1999; CASSANY et al., 2002; CASSANY; MORALES, 2009; LOMAS, 2015; LOMAS; OSORO; TUSÓN, 1993; LÓPEZ VALERO; ENCABO, 2001, 2016; MARTÍNEZ EZQUERRO, 2013; PÉREZ; ZAYAS, 2007; QUILES CABRERA, 2007; QUILES CABRERA; CAIRE, 2013).

En el desarrollo de las prácticas académicas, el alumno produce constantemente discursos orales y escritos que muestran la elaboración del conocimiento y el nivel de dominio de las competencias comunicativas. Esas producciones deberían ser composiciones correctas, tanto estructural como lingüísticamente. La escritura tiene un potencial epistémico, porque no es solo un medio de comunicación, sino un instrumento para desarrollar y transformar el propio saber (CARLINO, 2003). Lamentablemente, hallamos textos con graves carencias de variada tipología (normativa, cohesión, coherencia, presentación, estilo...), en un contexto en el que al deficiente dominio de la expresión escrita le acompaña la incorrección ortográfica y normativa (GRIJELMO, 1998).

Nos preocupa, de forma concreta en el presente estudio, la ausencia de adecuación que se percibe en ciertos trabajos académicos, desarrollados en un contexto en el que se emplea el lenguaje culto y el registro formal y donde, en cambio, hallamos el registro informal con sus característicos rasgos lingüísticos (reiteraciones léxicas, giros estilísticos coloquiales, proliferación de conectores pragmáticos, intensificadores, deícticos...), propios de un discurso no planificado próximo a la lengua oral (QUILES CABRERA, 2009). Se aprecia un distanciamiento del exigido nivel culto y se comprueba que el alumno ha quebrantado ciertas convenciones que provocan que el acto comunicativo (trabajos, discurso) desde la perspectiva del interlocutor (profesor) conlleve 
cierto fracaso (se rompen sus expectativas porque el empleo del registro es inadecuado). El universitario forma parte de una comunidad discursiva - la académica - que le hace participar de un ámbito específico de conocimiento con sus propias convenciones textuales y genéricas (TEJERINA; SÁNCHEZ, 2009), y la falta de adecuación entre el uso y la situación muestra la necesidad de fomentar la mencionada competencia lingüística.

En cuanto al método lingüístico aplicado para analizar los aspectos mencionados, partimos de que el conocimiento de nociones y técnicas de participación en la cultura discursiva formal toma sus procedimientos y recursos de la didáctica de la lengua, en cuanto que facilita estrategias de aprendizaje lingüístico que desarrollan las habilidades comunicativas de la composición textual. Las fases de escritura junto con sus propiedades se asientan en la retórica (elocutio) y en la gramática normativa como ciencias que aportan las técnicas para la correcta instrucción. El uso debe ser adecuado a la situación, y desde este enfoque revisamos las aportaciones de los estudios del español coloquial que tratan la oralidad en la escritura (BEINHAUER, 1985; BRIZ, 1996, 1998, 2003, 2018; CAMPS; CASTELLÓ, 2013; CASADO VELARDE, 2005, 2015; GÓMEZ TORREGO, 1992, 2011; LÁZARO CARRETER, 1997; NARBONA, 2019; RAE, 2009, 2010, 2013, 2018; TUSÓN, 1991; VIGARA, 1980).

A la luz de estas premisas, ponemos de relieve la importancia que tiene el dominio de la competencia lingüística en la alfabetización académica para la formación inicial del profesorado $y$, de forma paralela, lo ejemplificamos con un estudio de caso centrado en el análisis de rasgos lingüístico-discursivos presentes en las tareas del alumnado. Consideramos que este dominio es todavía más exigible para los docentes en formación (SÁNCHEZ LISSEN; SÁNCHEZ FRANCO, 2019), puesto que, como futuros profesores, se enfrentarán a continuas situaciones de comunicación en las que serán ineludibles modelos competenciales.

\section{Metodología}

\subsection{Marco teórico}

En la presente investigación analizamos los usos lingüísticos empleados por los alumnos en sus trabajos escritos (tareas, informes, exámenes, etc.) que son inadecuados en contextos formales. Las marcas de oralidad son frecuentes en estos discursos y reflejan

Educ. Form., Fortaleza, v. 6, n. 1, e3502, jan./abr. 2021

DOI: https://doi.org/10.25053/redufor.v6i1.3502

https://revistas.uece.br/index.php/redufor/index 
la lengua cotidiana hablada por los jóvenes en su comunicación informal (ZIMMERMANN, 1996). Como sabemos, en el discurso académico se emplea la lengua común en su variedad culta y registro formal, y no tienen cabida los "desvíos" del habla oral (BRIZ, 1996). Estos relajamientos lingüísticos de los futuros profesores concitan la necesidad de desarrollar estrategias de comunicación y de promover actitudes metacognitivas.

El análisis realizado de los rasgos de oralidad tiene como marco general, según se ha explicado, la alfabetización (concretamente, de maestros en formación) y considera que los textos académicos son estructuras específicas que requieren el dominio de las destrezas lingüísticas desde un enfoque comunicativo, mediante el aprendizaje discursivo que aborda la didáctica de la lengua. El proceso textual es una tarea compleja que debe realizarse de forma procesual y planificada (ALVAR EZQUERRA et al., 1999; MARTíNEZ DE SOUSA, 2000; REGUEIRO; SÁEZ, 2013; REYES, 2008; SERRANO, 2002a, 2002b), organización que responde en retórica clásica a las partes artis o fases de composición textual (memoria y actio pertenecen a las destrezas orales). Los modelos que propone la nueva retórica o la didáctica de la expresión escrita implican la mejora del proceso, sobre todo en el análisis de la situación de comunicación específica, en el uso de los borradores, en las revisiones y en la elocutio o formulación verbal del discurso que ya propugnaron los clásicos (ALBADALEJO, 1989; LAUSBERG, 1987; MORTARA GARAVELLI, 1991; SPANG, 2005).

Estos enfoques conforman el marco metodológico discursivo aplicado en la instrucción competencial del estudiante, y su fin, según hemos indicado, pretende que los maestros en formación desarrollen adecuadamente sus competencias lingüísticas. Mostramos en los siguientes epígrafes la metodología aplicada para la obtención y organización de los datos del corpus, así como el perfil de los informantes y el tipo de muestras analizadas.

\subsection{Contextualización y participantes}

Teniendo en cuenta que el fin de la investigación es recoger un corpus real de datos extraídos de las tareas escritas realizadas por los estudiantes, incluimos dos años académicos y diversos trabajos que aseguran un continuum de elaboración discursiva en su contexto general y en una situación real. Ofrecemos, por tanto, unos registros que se 
analizan en el desarrollo habitual de la asignatura. Concretamente, para analizar los rasgos del lenguaje oral, se han recogido y vaciado las muestras o tareas académicas redactadas por los 160 informantes que constituyen los dos grupos de alumnos de la asignatura de segundo curso, "Didáctica de la Lengua Castellana y su Literatura", del Grado en Educación Primaria, durante los cursos 2017/2018 y 2018/2019. La razón por la que no se muestra un estudio comparativo entre ambos grupos (80 estudiantes cada año) responde a que no se apreciaron diferencias notables en los usos lingüísticos; por tanto, ambos cursos constituyen un solo grupo a efectos de cómputo de variables.

En cuanto a las características de los alumnos, 94 son mujeres (59\%) y 66 varones ( $41 \%) ; 148$ estudiantes tienen edades comprendidas entre 19 y 21 años $(92,5 \%)$, ocho se hallan entre 26 y 27 (5\%) y cuatro entre 40 y 44 años $(2,5 \%)$. En cuanto a la matriculación, hay 20 alumnos en segunda convocatoria. Los resultados fueron los siguientes: aprobaron el $20 \%$, se obtuvieron cuatro sobresalientes, 30 notables y el resto correspondió a aprobados. Son grupos heterogéneos que muestran, grosso modo, tres perfiles: alumnos muy implicados (los mejores resultados, los de más edad y con constatado hábito lector), estudiantes medianamente comprometidos (los aprobados) y discentes poco interesados (no les gusta la titulación, tienen otras expectativas académicas que no han podido alcanzar por la baja calificación obtenida en la Evaluación del Bachillerato para el Acceso a la Universidad - EBAU). En relación con el hábito lector, téngase en cuenta que el fomento del mismo no solo permite educar en valores, ampliar conocimientos, formar personas críticas y responsables (CARIDE; CARBALLO; GRADAÍLLE, 2018) y aproximarse a otras experiencias de vida (MARTOS NÚÑEZ; RÖSING, 2009), sino que es una herramienta imprescindible para la mejora de la expresión escrita (LÓPEZ VALERO; ENCABO, 2016), y así se aprecia en los resultados obtenidos.

Los instrumentos utilizados para la recogida de muestras durante los dos cursos académicos fueron, según se ha indicado, trabajos realizados durante el desarrollo de la asignatura, que estructuralmente son cuestionarios individuales con respuesta abierta. Las 320 muestras procedían de dos tareas de cada alumno en las que se desarrollaba principalmente el discurso expositivo-argumentativo; si bien recogimos el mencionado número de ejercicios, precisamos que para realizar el cómputo de sus rasgos se consideraron como si fueran 160 muestras (el número de estudiantes), porque cada 
informante aporta su trabajo como una amplia unidad de producción discursiva. La primera actividad correspondía a la recensión de un artículo de Didáctica de la Lengua, y la segunda, a un cuestionario de cinco preguntas reflexivas sobre hábitos y competencias lectoras y, así mismo, al desarrollo de una propuesta de intervención didáctica a partir de la lectura de una novela. La vasta muestra ofrece un completo material desde la perspectiva de la lingüística discursiva académica, porque enfrenta al alumno a la redacción de un texto en el que combina las reflexiones específicas con el conocimiento científico de la materia a partir de la propuesta de intervención docente. El extenso corpus se fue registrando y analizando a medida que se realizaban las correcciones pertinentes.

Mostramos, por tanto, los rasgos lingüísticos próximos al lenguaje oral más frecuentes y característicos de la población informante. Dada la naturaleza de la investigación del presente estudio de caso, nos centramos en una metodología cualitativa focalizada en el estudio y contextualización - en los casos precisos - de las muestras para describir sus características en relación con la especificidad de los rasgos de la composición escrita en el contexto académico formal y en la competencia lingüístico-discursiva de los informantes. El análisis que realizamos responde, por tanto, a un estudio descriptivo de caso que nos pone en relación directa con la realidad de dos grupos similares y concretos de estudiantes, cuestión que no significa que sea inicialmente extrapolable a otros ámbitos. Pero si tenemos en cuenta que "[...] la cuestión de la generalización de los estudios [...] no radica en una muestra probabilística extraída de una población a la que se pueda extender los resultados, sino en el desarrollo de una teoría que puede ser transferida a otros casos" (MARTÍNEZ CARAZO, 2006, p. 173), entendemos que los datos extraídos y las tareas nos permiten aplicar la investigación en otros grupos y contextos de similar naturaleza, que podrían ser contrastados y, por tanto, ofrecerían más información que completaría esta línea de investigación.

\section{Resultados y análisis de datos}

Para organizar el corpus de los rasgos del lenguaje oral, partimos del enfoque que la gramática normativa y los estudios de análisis del discurso aportan sobre los fenómenos y las características del lenguaje coloquial (BEINHAUER, 1985; BRIZ, 1996, 1998; GÓMEZ TORREGO, 2011), el de nuestros textos analizados. Ya hemos indicado 
que una de las preocupaciones de los discursos examinados es su rasgo de "proximidad a la lengua oral coloquial" - algo impropio de contextos académicos -, que muestra un inadecuado uso del exigido registro en ámbito formal y que denota que el estudiante no se adapta a la situación de comunicación. Las interrelaciones entre lo hablado y lo escrito surgen como modos de verbalización determinados por las condiciones de comunicación, y nunca deberían practicarse en nuestro campo de estudio. Briz (1998, p. 25) indica que en los registros:

[EI] contexto de comunicación regula y marca de algún modo las conductas lingüísticas y extralingüísticas de los hablantes, los cuales suelen esforzarse en acomodar en mayor o menor grado sus actos diarios de comunicación a la situación precisa en que tienen lugar. En efecto, un estudiante, por ejemplo, no habla del mismo modo cuando conversa con sus compañeros fuera del aula que con el profesor durante la clase.

\subsection{Clasificación de los rasgos lingüísticos de las muestras}

Para organizar los rasgos del registro coloquial de las muestras que conforman el corpus, hemos establecido tres apartados, que corresponden a los niveles lingüísticodiscursivos (no incluimos signos de puntuación ni cuestiones tipográficas). Computamos, según hemos señalado, los recursos recogidos en las dos prácticas de cada estudiante como una unidad (cada informante aporta datos que constituyen un continuum estilístico) y valoramos la presencia de los nueve rasgos en la doble muestra de los 160 informantes. Así, la Figura 1 ofrece la suma de los ítems registrados en la producción (entendida la suma de tareas como unidad, esto es, 160 muestras) de cada alumno.

Figura 1 - Resultados de los rasgos de las muestras

\begin{tabular}{|c|c|c|c|}
\hline \multicolumn{2}{|c|}{ Rasgos de las muestras (lengua oral/registro informal) } & \multicolumn{2}{c|}{$\begin{array}{c}\text { Número / porcentaje de estudiantes } \\
\text { que los emplean }\end{array}$} \\
\hline \multirow{3}{*}{$\begin{array}{c}\text { Nivel } \\
\text { morfosintáctico }\end{array}$} & Conectores pragmáticos & 160 & $100 \%$ \\
\cline { 2 - 4 } & Intensificadores & 140 & $87 \%$ \\
\cline { 2 - 4 } & Atenuantes & 143 & $89 \%$ \\
\hline \multirow{nyyy}{*}{$\begin{array}{c}\text { Nivel estructural: } \\
\text { organización del } \\
\text { discurso }\end{array}$} & $\begin{array}{c}\text { Concatenticos } \\
\text { pocos nexos subordinantes e hipérbatos }\end{array}$ & 160 & $100 \%$ \\
\hline \multirow{2}{*}{$\begin{array}{c}\text { Nivel léxico- } \\
\text { semántico }\end{array}$} & Pobreza léxica & 150 & $100 \%$ \\
\cline { 2 - 4 } & Reiteración lingüística & 160 & $100 \%$ \\
\cline { 2 - 4 } & Léxico & 160 & $100 \%$ \\
\hline
\end{tabular}

Fuente: Elaboración propia (2020).

Educ. Form., Fortaleza, v. 6, n. 1, e3502, jan./abr. 2021

DOI: https://doi.org/10.25053/redufor.v6i1.3502

https://revistas.uece.br/index.php/redufor/index 


\subsection{Uso de los recursos propios del lenguaje oral}

Mostramos los rasgos lingüístico-discursivos extraídos de las muestras o textos que corresponden a fenómenos en los que se aprecia la contaminación oral propia del registro coloquial. Se han numerado los trabajos a partir de la organización de los informantes, esto es, del 1 al 80 (curso 2018/2019) y del 81 al 160 (curso 2017/2018). Veamos los respectivos niveles.

\section{a) Rasgos lingüísticos del nivel morfosintáctico}

1. Conectores pragmáticos. El más frecuente responde a es que, tiene un doble sentido puesto que no solo vincula enunciados sino también los enunciados con la enunciación: no me gustan los libros es que nunca los acabo (94); me gusta leer, lo que pasa es que no tengo tiempo para leer (140).

2. Intensificadores. Son estrategias retóricas que dan a entender más de lo que realmente se dice. Se utilizan variados recursos:

- Redundancias: la terminé toda entera (1); solemos hacer de manera muy habitual (20); siempre aprendes nuevas cosas (82).

- Sinónimos consecutivos: normal y corriente (1); utilizar y emplear (30); llame su atención y les atraiga (49); entretenida y amena (66); muestren y reflejen (67); entendido y comprendido (67); disfrutar y gozar (93); a todos y cada uno de los que hay (128).

- Adverbios o fórmulas adverbiales de relleno: realmente (43); personalmente (57); claramente (64); sinceramente (80); a decir verdad (131); de verdad me gustaba leer (159).

3. Atenuantes. Constituyen una estrategia conversacional que mitiga la fuerza significativa de una palabra o de una acción: no me hacía mucha gracia leerlos (64); no dedicó tanto tiempo como debería (67); sé más o menos lo que les gusta (106); es poco divertido (143); de manera no obligada, leerlo poco a poco (154).

4. Deícticos. La deixis personal responde al carácter egocéntrico de la conversación coloquial. La presencia del yo hablante se manifiesta de forma reiterada; ensalza y eleva la imagen, a veces en perjuicio del tú, es la personalización del yo (BRIZ, 
1996, p. 56). Apreciamos secuencias enfatizadoras mediante el uso de la primera persona: si yo soy sincero (5); yo diría que (28); que yo recuerde (86); yo al ser tan pequeña (89); los escogía personalmente según mi propio gusto (126); me motivó a mí (137). También hallamos el deíctico personal desplazado, es el caso del uso del tú impersonal; el yo aparece latente bajo la máscara del propio tú en un intento de atenuar su papel:

Para mí la lectura es un tipo de música mejorada. La música llena los silencios y te acompaña en cada uno de los momentos de la vida (sean buenos o malos). En cambio, tú das sentido a las palabras en la lectura. Ahí están, pero tienes tú que leerlas y darles sentido. (26).

Este carácter egocéntrico propio del registro informal de la lengua oral responde al yo, aquí, ahora ("ante ti") y constituye un triple centro deíctico personal, espacial y temporal recurrente. En cuanto al espacio, veamos algunos ejemplos: aquí podrían exponer los libros (40); se llevan los argumentos a esta clase (50). En relación con el tiempo, hallamos los ejemplos del día a día (56); a día de hoy (97); hoy en día (151).

5. Relaciones temporales. Se registran desplazamientos temporales hacia el presente en un intento de mostrar los hechos desde el "ahora": el problema es que nunca los acababa, 44; en Primaria se da por encima (110).

\section{b) Recursos estructurales. Formulación y organización del discurso}

La ausencia de planificación y el escaso conocimiento de la adecuación para establecer la producción textual determinan una sintaxis no convencional y una estructura gramatical caracterizada por la concatenación de enunciados, paráfrasis, pocos nexos subordinantes, párrafos breves y descoordinados, y empleo de hipérbatos. Responden a un discurso directo, sin planificar y con información desorganizada. Veamos algunos ejemplos:

Hay alumnos que tienen más facilidades para leer, ya bien porque han leído y les
gusta o porque ya han despertado ese interés por la lectura y les engancha, y ya
tienen un estilo de lectura que les gusta, pero, para los que están empezando y
no tienen ese interés, es importante empezar con historias cortas, divertidas y
entretenidas y sobre todo hacerles ver que leer es importante. Proporcionar libros
de sus intereses y acordes con la edad en el cual el lector pueda sentirse
identificado y pueda hacer volar su imaginación. Es importante que el alumno 
pueda sentirse identificado y meterse en el papel y sobre todo hacer desde el principio que se enganche. (38).

Mostrándoles lo importante que es la lectura para tener un vocabulario más rico, para desarrollar la memoria, para no tener tantas faltas de ortografía y sobre todo para entretenerse y divertirse. También animándolos a que sean ellos quienes escojan el libro a leer, ya que hay libros de muchos tipos y a unos les puede gustar los libros de aventuras, a otros los de miedo etc. Lo verdaderamente importante es comenzar desde pequeño e ir probando diferentes registros para dar con el que verdaderamente les guste. (59).

\section{c) Rasgos lingüísticos del nivel léxico-semántico}

La pobreza léxica es característica de la lengua coloquial, es decir, que con escasos recursos de palabras se consigue el objetivo comunicativo previsto. Destaca en este nivel la reducción y selección que sufre el vocabulario común, así como el empleo de unidades polisémicas y de perífrasis y paráfrasis explicativas que cubren las carencias de disponibilidad léxica de los hablantes. Los rasgos destacables son los siguientes:

1. Pobreza léxica. Se emplean términos de amplitud y vaguedad semántica, son palabras comodín (verba omnibus), bien sustantivos (cosa, cuestión...), bien verbos polisémicos (hacer, poner, dar...). Mostramos algunos ejemplos: visto así la cosa cambia (123); no dicen qué cosa les ha gustado (143); hacen una ficha (1), un resumen (6), una reflexión (31), unas actividades (1), una lectura (36), una encuesta (37), una lista (60), unas preguntas (80), una carta (95); ponen los nombres (7), deberes (136); y dan el tema (13), el papel de la obra (105).

La adjetivación inexpresiva ofrece calificativos sin matiz, esto es, semánticamente "semivacíos" por su empleo frecuente y amplio significado. Son comodines de moda que denotan un escaso repertorio idiomático. Los empleados de forma general son los siguientes: pequeño, interesante, especial, importante, bueno, malo, fundamental, grande, bonito, feo, pesado, extenso, sencillo, enorme, esencial y considerable.

2. Reiteración lingüística. El discurso poco planificado y el valor enfático del registro oral contribuyen al uso de inelegantes repeticiones de vocablos, rasgo que hemos recogido en todas las muestras. Veamos algunos ejemplos: 
Los alumnos de cursos iniciales pueden iniciarse en el gusto por la lectura a través de la imitación y, si nos ven leer a los profesores o a sus padres, ellos se animarán a leer también. (5).

Me gusta leer, pero no me gusta leer cualquier cosa. Me inclino más por leer novela dentro del género narrativo y nunca me ha gustado mucho leer novela policiaca. Disfruto leyendo novela histórica. (35).

También se registran circunloquios verbales: ponerme a ello (11); eso se hacía notar (8); entré en contacto (13); fue siendo un bebé (22); dar lugar a la imaginación (25); van cumpliendo una edad (31); el hecho de investigar sobre leer (45); doy con alguno (50); se va haciendo consciente (139).

3. El léxico es abierto (de naturaleza "ecléctica") y da entrada a voces de moda, términos de lenguajes especiales y, sobre todo, del argot. Son numerosas las palabras que de la jerga juvenil pasan al registro coloquial. Algunos ejemplos: una lectura que me marcase (28); fui una fanática de esa escritora (18); la profesora sabía manejar las clases (32). El recurrente empleo de términos escuchados, muchas veces, en los medios de comunicación (la producción escrita es una actividad estrechamente ligada a la reflexión metacognitiva y a la metalingüística) provoca desplazamientos semánticos: tengo indicios de lectura (38); es mejor no implantar nunca un libro (72); me tiene que enganchar y despertar mi interés (147).

También se recogen vocablos coloquiales: que les pique la intriga y se lancen a leerlo (4); siempre había algún espabilado que leía más rápido (7); me gustaba un montón leer (34); no me he parado a buscar un libro (38); dejar que campe a sus anchas (87); espero que se me pase ese agobio (99); la lectura obligatoria tira para atrás (103); cuando llegábamos se daba y punto (129); me encantó aunque era de esperar (146).

Se aprecia, asimismo, tendencia a la intensificación, llegando en algunos casos al uso de la hipérbole: me hicieron el peor regalo de la historia (4). Véase este fragmento, entre otros muchos recogidos:

\footnotetext{
Pero la principal baza es mostrar un interés enorme por parte del profesor hacia la lectura, mostrarles que la lectura puede apasionar, que la imaginación con ella no tiene límites, que pueden descubrir mundos propios y extraños teniendo una conexión especial con el cuento leído. (30).
} 
En suma, se aprecian usos coloquiales de la lengua que denotan una redacción rápida, a veces inapropiadamente expresiva, y con ausencia de planificación y adecuación textuales.

\section{Discusión y consideraciones finales}

El discurso bien escrito constituye una habilidad compleja que requiere precisa técnica y constante práctica. A partir de la investigación realizada, apreciamos la necesidad de formar a los alumnos universitarios en el fomento de las destrezas comunicativas en el marco epistémico de la alfabetización académica. Una cuestión que quizá no tienen en cuenta los docentes de niveles anteriores (GUTIÉRREZ RIVERO; GAVIÑO RODRíGUEZ, 2020) al universitario es que las tareas se tornan más complejas según se avanza en los estadios educativos. Los trabajos deben escribirse académicamente, es decir, requieren no solo el dominio de la competencia lingüística (normas ortográficas, gramaticales, léxico, etc.), sino también el conocimiento de las pautas que regulan el género elegido, el control del proceso de escritura y la adecuación de todos sus constituyentes comunicativos. En las tareas discursivas de los estudiantes, se constata que no conocen (y no aplican), por lo general, los requisitos de la situación de enunciación, puesto que no respetan sus características; cuando se escribe, no basta con conocer solo el tema, sino que es preciso saber también las variables situacionales que condicionan el discurso. Las prácticas textuales deben formar en el valor de una buena comunicación escrita, que depende esencialmente del propósito, del contexto y del lector, así como del dominio de las destrezas lingüísticas (que exigen una formulación verbal propia del discurso científico), según se ha indicado.

En los trabajos académicos hemos recogido abundantes rasgos lingüísticos pertenecientes al lenguaje oral conversacional, uso propio de contextos informales en los que predomina la espontaneidad. Los fenómenos registrados demuestran una constante inadecuación a la situación comunicativa, pues el trabajo desarrollado en el ámbito académico precisa el empleo de la lengua culta. Los escritos analizados presentan escasa planificación (se desatienden las fases de producción discursiva) y emplean rasgos del registro informal conversacional (conectores pragmáticos coloquiales, 
intensificadores, atenuantes, deícticos principalmente personales, enunciados concatenados, léxico pobre y repeticiones constantes).

Estos empleos generalizados en las prácticas académicas nos hacen reflexionar sobre la posible influencia de los modelos discursivos practicados en la comunicación oral cotidiana en conversaciones informales con registro coloquial. Los paradigmas de estos estudiantes (CAMPOS F.-FÍGARES, 2016; PALMER; CAMPOS F.-FÍGARES, 2019) proceden de las lecturas literarias - téngase en cuenta que las TIC son idóneas para fomentar la lectura (ROMERO OLIVA; HEREDIA PONCE; TRIGO IBÁÑEZ, 2020) y las académicas, de otros textos escritos (periódicos, revistas, cómics, notas personales, etc.) y de los medios informáticos. Muchas voces alertan sobre el peligro de los espacios digitales como nefastos modelos para las prácticas lingüísticas, pero el problema no radica en la habitual utilización en estos medios de comunicación, porque, según hemos indicado, la adecuada formación discursiva selecciona el preciso empleo (MARTÍNEZ EZQUERRO, 2019, p. 126) exigido por la situación:

\begin{abstract}
En el caso de la comunicación en la cibergalaxia, es manifiesto que el cambio de registro y el nivel de lengua utilizados ad hoc por el emisor son elementos impuestos por el contexto que preservan de la amenaza en su uso generalizado. Las personas que poseen un conocimiento deficitario de la lengua lo demostrarán tanto en canales orales como impresos (o escritos) y en cualquier situación, circunstancia que siempre ha existido y que no ha supuesto un peligro para nuestro idioma que, además, se halla respaldado por la normativa.
\end{abstract}

Asimismo, el deficiente hábito lector cercena las consiguientes posibilidades de desarrollo y fomento de las destrezas propias de la expresión escrita. Es preciso desarrollar la competencia comunicativa como "[...] herramienta imprescindible de [la] futura actividad docente" (MARTíNEZ EZQUERRO, 2012, p. 94), así como formar en el fomento de las destrezas lingüístico-discursivas. La planificación de estrategias y métodos que proporciona la alfabetización académica permite que el alumno obtenga mejores resultados en todas las materias. Serían necesarios programas de acompañamiento formativo de las particularidades discursivas de cada campo del conocimiento porque la producción textual no es un problema que deban solucionar exclusivamente los profesores del ámbito lingüístico; el fomento de estas competencias está directamente vinculado al desarrollo del pensamiento y, por tanto, al aprendizaje en todas las disciplinas. Deberían aplicarse métodos coordinados para fortalecer estas habilidades, que son transversales a todas las ramas de conocimiento, y tendrían que 
estar apoyados en políticas institucionales. Por otro lado, los estudiantes escribirían discursos adecuados si se realizara un proceso de diagnóstico-prescripción-evaluación, método que ayudaría a establecer la adquisición del nivel de competencias con el fin de tomar decisiones sobre las estrategias de enseñanza más adecuadas.

El valor de los resultados de este estudio debe considerarse con limitaciones. Los datos obtenidos de las muestras no han pretendido generalizar los resultados, pues podrían aplicarse a todos los cursos, si bien consideramos que en los dos primeros años académicos es más efectivo su análisis porque se detectan antes las deficiencias $\mathrm{y}$, de esta forma, se pueden aplicar las correspondientes medidas de formación (JUNGES; KETZER; OLIVEIRA, 2018) mediante programas de alfabetización. Hemos pretendido ofrecer un espacio de reflexión sobre el adecuado uso de la lengua escrita y el desarrollo de la competencia lingüístico-discursiva de los futuros maestros y, por otro lado, hemos destacado la necesidad de programar una formación explícita que solvente las mencionadas carencias. El desarrollo de los modelos competenciales comunicativos bien se podría abordar desde una perspectiva transdisciplinar.

\section{Referencias}

ALBADALEJO, T. Retórica. Madrid: Síntesis, 1989.

ALVAR EZQUERRA, M. et al. Manual de redacción y estilo. Madrid: Istmo, 1999.

BALLANO, I.; MUÑOZ, I. (coord.). Escribir en el contexto académico. Bilbao: Universidad de Deusto, 2014.

BALLANO, I.; MUÑOZ, I. (coord.). La escritura académica en las universidades españolas. Bilbao: Universidad de Deusto, 2015.

BEINHAUER, W. El español coloquial. Madrid: Gredos, 1985.

BOEGLIN, M. Leer y escribir en la universidad: del caos al texto estructurado. Bogotá: Magisterio, 2008.

BRIZ, A. Al hilo del español hablado: reflexiones sobre pragmática y español coloquial. Sevilla: Universidad de Sevilla, 2018.

BRIZ, A. El español coloquial en la conversación: esbozo de pragmagramática. Barcelona: Ariel, 1998. 
BRIZ, A. El español coloquial: situación y uso. Madrid: Arco, 1996.

BRIZ, A. La interacción entre jóvenes: español coloquial, argot y lenguaje juvenil. In: ELIZONDO, E.; SÁNCHEZ MÉNDEZ, M. (ed.) Lexicografía y lexicología en Europa y América: homenaje a Günter Haensch. Madrid: Gredos, 2003. p. 141-154.

CAMPOS F.-FÍGARES, M. Clubes de lectura e interculturalidad. In: MARTÍNEZ EZQUERRO, A.; CAMPOS F.-FíGARES, M. (ed.). Cultura en la diversidad: educación lingüística y literaria en las aulas del siglo XXI. Barcelona: Octaedro, 2016. p. 153-165.

CAMPS, A.; CASTELLÓ, M. La escritura académica en la universidad. Revista de Docencia Universitaria, Valencia, v. 11, n. 1, p. 17-36, 2013.

CANALE, M. De la competencia comunicativa a la pedagogía comunicativa del lenguaje. In: LLOBERA, M. (coord.). Competencia comunicativa: documentos básicos en la enseñanza de lenguas extranjeras. Madrid: Edelsa, 1995. p. 63-82.

CARIDE, J. A.; CARBALLO, M. B.; GRADAÍLLE, R. Leer en tiempos de ocio: los estudiantes, futuros profesionales de la educación, como sujetos lectores. Ocnos: Revista de Estudios sobre Lectura, Castilla-La Mancha, v. 17, n. 3, p. 7-18, 2018.

CARLINO, P. Alfabetización académica diez años después. Revista Mexicana de Investigación Educativa, Ciudad de México, DF, v. 18, n. 57, p. 355-381, 2013.

CARLINO, P. Alfabetización académica: un cambio necesario, algunas alternativas posibles. Educere, Mérida, v. 6, n. 20, p. 409-420, 2003.

CARLINO, P. Escribir, leer y aprender en la universidad: una introducción a la alfabetización académica. Buenos Aires: Fondo de Cultura Económica, 2005.

CASADO VELARDE, M. El castellano actual: usos y normas. Pamplona: Eunsa, 2005.

CASADO VELARDE, M. La innovación léxica en el español actual. Madrid: Síntesis, 2015.

CASSANY, D. Construir la escritura. Barcelona: Paidós, 1999.

CASSANY, D. Describir el escribir. Barcelona: Paidós, 1989.

CASSANY, D. et al. Enseñar lengua. Barcelona: Graó, 2002.

CASSANY, D.; MORALES, O. Leer y escribir en la universidad: los géneros científicos. In: CASSANY, D. (comp.). Para ser letrados: voces y miradas sobre la lectura. Barcelona: Paidós, 2009. p. 109-128.

GÓMEZ TORREGO, L. El buen uso de las palabras. Madrid: Arco, 1992. 
GÓMEZ TORREGO, L. Hablar y escribir correctamente: gramática normativa del español actual. Madrid: Arco, 2011.

GRIJELMO, Á. Defensa apasionada del idioma español. Madrid: Taurus, 1998.

GUTIÉRREZ RIVERO, A.; GAVIÑO RODRÍGUEZ, V. A marca da Real Academia Espanhola nos manuais de ensino da língua para o Ensino Secundário. Educação \& Formação, Fortaleza, v. 5, n. 3, p. 1-21, 2020.

HYMES, D. H. Hacia la competencia lingüística. París: Hatier, 1984.

JUNGES, F. C.; KETZER, C. M.; OLIVEIRA, V. M. A. Formação continuada de professores: saberes ressignificados e práticas docentes transformadas. Educação \& Formação, Fortaleza, v. 3, n. 9, p. 88-101, 2018.

LAUSBERG, F. Manual de retórica. Madrid: Gredos, 1987.

LÁZARO CARRETER, F. El dardo en la palabra. Madrid: Galaxia Gutenberg-Círculo de Lectores, 1997.

LOMAS, C. (coord.). Fundamentos para una enseñanza comunicativa del lenguaje. Barcelona: Graó, 2015.

LOMAS, C.; OSORO, A.; TUSÓN, A. Ciencias del lenguaje, competencia comunicativa y enseñanza de la lengua. Barcelona: Paidós, 1993.

LÓPEZ VALERO, A.; ENCABO, E. El desarrollo de habilidades lingüísticas: una perspectiva crítica. Granada: Universitario, 2001.

LÓPEZ VALERO, A.; ENCABO, E. Fundamentos didácticos de la lengua y la literatura. Madrid: Síntesis, 2016.

MARTÍNEZ DE SOUSA, J. Manual de estilo de la lengua española. Gijón: Trea, 2000.

MARTÍNEZ CARAZO, P. El método de estudio de caso. Pensamiento y Gestión, Barranquilla, n. 20, p. 165-193, 2006.

MARTÍNEZ EZQUERRO, A. Competencia comunicativa y transversalidad en contextos multiculturales de L2. In: BLECUA, B. et al. (ed.). Plurilingüismo y enseñanza de ELE en contextos multiculturales. Gerona: Universidad de Gerona, 2013. p. 557-568.

MARTÍNEZ EZQUERRO, A. Sobre usos lingüísticos a la luz de la cultura oral y letrada en la era digital. In: CAMPOS FERNÁNDEZ-FÍGARES, M.; QUILES CABRERA, M. C. (ed.). Repensando la didáctica de la lengua y la literatura: líneas emergentes de investigación. Madrid: Visor, 2019. p. 113-129. 
MARTOS NÚÑEZ, E.; RÖSING, T. M. K. (coord.). Prácticas de lectura y escritura. Passo Fundo: Universidad de Passo Fundo, 2009.

MONTOLíO, E. (dir.). Manual de escritura académica y profesional. Barcelona: Ariel, 2014.

MORTARA GARAVELLI, B. Manual de retórica. Madrid: Cátedra, 1991.

MOYANO, E. I. Escritura académica a lo largo de la carrera: un programa institucional. Revista Signos, Lajeado, v. 43, n. 74, p. 465-488, 2010.

MOYANO, E. I. La enseñanza de la lectura y la escritura académicas mediante programas a lo largo del curriculum universitario: opción teórica, didáctica y de gestión. D.E.L.T.A., São Paulo, v. 34.1, p. 235-267, 2018.

NARBONA, A. El estudio de la sintaxis del español coloquial (balance provisional). Normas, Valencia, v. 9, p. 138-159, 2019.

PALMER, Í.; CAMPOS F.-FÍGARES, M. Adivinanzas en el aula de ELE: literatura oral, patrimonio e innovación educativa. Tejuelo, Ciudad de México, DF, v. 30, p. 289-316, 2019.

PÉREZ, P.; ZAYAS, F. Competencia en comunicación lingüística. Madrid: Alianza, 2007.

QUILES CABRERA, M. C. Interferencias oralidad-escritura en el discurso formal: una aproximación empírica en el ámbito universitario. In: CORTÉS RODRíGUEZ, L. (coord.). Discurso y oralidad: homenaje al profesor José Jesús de Bustos Tovar. Madrid: Arco, 2007. p. 847-886.

QUILES CABRERA, M. C. Prácticas de escritura en la educación superior: del ámbito académico al lenguaje creativo. In: MARTOS, E.; RÖSING, T. M. K. (coord.). Prácticas de lectura y escritura. Passo Fundo: Universidad de Passo Fundo, 2009. p. 55-76.

QUILES CABRERA, M. C.; CAIRE, M. P. Sobre el texto y la competencia cultural en la Educación Superior: aproximación a un aula de ELE. Porta Linguarum, Granada, v. 19, p. 199-218, 2013.

RAE. (BOSQUE, I.). Nueva gramática de la lengua española. Madrid: Espasa, 2009.

RAE. El buen uso del español. Madrid: Espasa, 2013.

RAE. Libro de estilo de la lengua española. Madrid: Espasa, 2018.

RAE. Ortografía de la Lengua Española. Madrid: Espasa, 2010.

REGUEIRO, M. L.; SÁEZ, D. M. El español académico: guía práctica para la elaboración de textos académicos. Madrid: Arco, 2013. 
REYES, G. Cómo escribir bien en español. Madrid: Arco, 2008.

ROMERO OLIVA, M. F.; HEREDIA PONCE, H.; TRIGO IBÁÑEZ, E. Las TIC en el fomento lector de los adolescentes. Un estudio de caso desde las creencias docentes. Contextos Educativos, Logroño, v. 25, p. 105-125, 2020.

SÁNCHEZ LISSEN, E.; SÁNCHEZ FRANCO, M. Una mirada a la trayectoria histórica de la formación de maestros en España durante los siglos XIX y XX. Educação \& Formação, Fortaleza, v. 4, n. 10, p. 18-49, 2019.

SERRANO, J. Cómo redactar tus exámenes y otros escritos de clase. Madrid: Anaya, 2002a.

SERRANO, J. Guía práctica de redacción. Madrid: Anaya, 2002b.

SPANG, K. Persuasión: fundamentos de retórica. Pamplona: Eunsa, 2005.

TEJERINA, I.; SÁNCHEZ, S. La escritura académica en la universidad. In: MARTOS, E.; RÖSING, T. M. K. (coord.). Prácticas de lectura y escritura. Passo Fundo: Universidad de Passo Fundo, 2009. p. 91-114.

TUSÓN, A. Las marcas de la oralidad en la escritura. Signos: Teoría y Práctica de la Educación, Barcelona, v. 12, p. 14-19, 1991.

VAN DIJK, T. A. Estructuras y funciones del discurso. Madrid: Siglo XXI, 1980.

VIGARA, A. M. Aspectos del español hablado. Madrid: SGEL, 1980.

ZIMMERMANN, K. Lenguaje juvenil, comunicación entre jóvenes y oralidad. In: KOTSCHI, T.; OESTERREICHER, W.; ZIMMERMANN, K. (coord.). El español hablado y la cultura oral en España e Hispanoamérica. Madrid: Ibeoamericana, 1996. p. 475-514.

\footnotetext{
Aurora Martínez Ezquerro, Universidad de La Rioja, Departamento de Filologías Hispánica y Clássica iDhttps://orcid.org/0000-0001-8323-1768

Profesora titular del área de Didáctica de la Lengua y la Literatura, Departamento de Filologías Hispánica y Clásicas (Universidad de La Rioja). Desarrolla su investigación en innovación docente aplicada en Lengua y Literatura; asimismo, sus conocimientos se centran en el ámbito de la lexicografía didáctica, la retórica aplicada y la lingüística competencial e intercultural. Ha publicado, entre otras monografías, Didáctica de las figuras retóricas, El camino de la lengua castellana, Música de las esferas-Literatura en el aula, Aprendizaje y enseñanza de Lengua Castellana y Literatura, La Educación en el valle del Ebro (ed.), Cultura en la diversidad (ed.), Enredos de palabras: gramática y uso de la lengua en nuevos espacios de comunicación (coautora con Quiles y Palmer), etc. Colabora con revistas de su especialidad y con editoriales educativas (Oxford University Press). Es miembro del Proyecto EDULECO, RIUL-UAL (I+D Transfiere). Ha sido coordinadora de Proyectos de Innovación Docente (Universidad de La Rioja) y colaboradora en la Consejería de Educación (Gobierno de La Rioja) en Proyectos de Innovación Educativa. Ha obtenido, entre otros, el Premio de Investigación Ciudad de Calahorra y el Primer Premio Nacional Pájaros de cuento (Editorial Everest).

Contribución de autoría: Escrita y revisión.

E-mail: aurora.martinez@unirioja.es
}

Educ. Form., Fortaleza, v. 6, n. 1, e3502, jan./abr. 2021

DOI: https://doi.org/10.25053/redufor.v6i1.3502

https://revistas.uece.br/index.php/redufor/index 
Editora responsable: Lia Machado Fiuza Fialho Pareceristas ad hoc: Antonio Gutiérrez Rivero y María Natalia Castillo Fadic

\section{Cómo citar este artículo (ABNT):}

MARTÍNEZ EZQUERRO, Aurora. Cuando se aproxima el lenguaje escrito al oral: competencias lingüísticas en el discurso académico del alumnado del grado en Educación Primaria. Educ. Form., Fortaleza, v. 6, n. 1, e3502, 2020. Disponible en: https://revistas.uece.br/index.php/redufor/article/view/3502

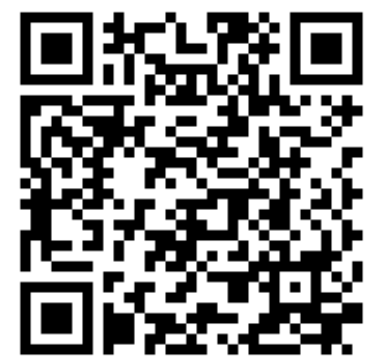

Recibido el 9 de julio de 2020.

Aceptado el 25 de agosto de 2020.

Publicado el 17 de noviembre de 2020. 